\title{
EL PROBLEMA DEL LENGUAJE PLÁSTICO: NOTAS SOBRE LA DOBLE ARTICULACIÓN DEL SIGNO PICTÓRICO
}

\author{
José M. Querol
}

(Madrid)

Hablar de lenguaje es hablar de comunicación, y viceversa. Toda comunicación humana se sustenta sobre un sistema específico de signos materiales que transcriben unos contenidos de índole diferente de la materia sobre la que se trasmiten.

Esto es una evidencia de la que nadie parece dudar, la magia de la transformación de los sonidos en imágenes mentales que generan la información sobre la naturaleza, y sobre sí mismo, al hombre, otorgándole así la posibilidad de transformar el mundo y realizarse como tal en la tarea, ha sido y es, desde la más remota antigüedad, objeto de estudio en función de su capital importancia para el desarrollo de nuestra especie.

De entre los sistemas utilizados en esta transferencia de conocimientos hay uno que sin lugar a dudas es el sistema raíz del proceso comunicativo humano: el sistema lingüístico. La capacidad de la palabra, del 
lenguaje, como trasmisor intermediario del hombre en su relación consigo mismo y con su entorno, hace posible la aprehensión de la simbólica del universo cultural, y, por tanto, su dominio.

Esta vieja tesis, que fue intuida desde la más remota antigüedad por las primeras culturas que dotaban a la palabra de poder efectivo sobre las $\cos ^{1}{ }^{1}$, fue probada y sometida a estudio ya por Cassirer en los años cincuenta de nuestro siglo.

Ahora bien, el sistema lingüístico, primer y fundamental sistema de comunicación humana, no es sin embargo el único mediante el cual una civilización construye la imagen de sí misma y del universo. Es posible definir, como hizo Yuri M. Lotman (1970: 20 y ss.), a este sistema de signos que otros han denominado lengua natural como proceso de semiotización primario, frente a otros sistemas de representación simbólica del mundo que utilizan otros soportes materiales distintos del signo lingüístico.

De hecho, existen diversas formas de comunicación sistemática de la información simbólica de la realidad que elaboran reglas, a veces paralelas a las reglas del sistema linguiístico, a veces divergentes a éste, mediante las cuales la comunicación tiene lugar. Negar la capacidad comunicativa de la representación pictórica, por entrar en el asunto que nos ocupa, sería negar evidencias como la función comunicativa de las pinturas rupestres o de las representaciones plásticas medievales de la Historia Sagrada que se encuentran en todas las catedrales.

A aquellos sistemas de comunicación no lingüísticos, Lotman (1970:20) los designa como procesos de semiotización secundarios, esto es, estructuras de comunicación que se superponen sobre el nivel lingüístico natural (mito, religión). Lotman, a través de la división de niveles en la comunicación (lengua natural, lenguajes artificiales y lenguajes secundarios de comunicación) estableció orden en la vieja discusión que es, en el fondo, el tema de este estudio: aquella vieja polémica que en nuestra cultura fue emblematizada por el lema horaciano ut pictura poesis y que no ha dejado de preocupar, si bien de manera intermitente, a la crítica y al pensamiento más serios de nuestra cultura ${ }^{2}$.

1 La veracidad de tal afirmación está atestiguada por la antropología contemporánea, basta echar un vistazo a las ya viejas páginas de La Rama Dorada de sir John Frazer [cfr. FRAZER (1890, ed. cast. 1986)], o a las mucho más recientes reflexiones sobre la palabra de Mircea Elíade (cfr. por ejemplo ELÍADE (1958, especialmente, para el asunto que nos ocupa: ed. cast. 1992. 73 y ss.) para tener una idea aproximada del valor que esta pudiera tener en los albores de las primeras civilizaciones.

2 En el origen del problema están Filostrato, Plinio el viejo, y el joven, Aristóteles y Horacio, pero, en lo que concierne al pensamiento moderno, en las mentes de todos 
La polémica más reciente de las suscitadas alrededor de la consideración de la comunicación visual como sistema de comunicación se ha centrado sobre el paralelismo de éste, en cuanto a organización interna, con respecto al sistema matriz de comunicación: el sistema lingüístico, y se ha venido encauzando a través de la discusión sobre la posibilidad o no de que el sistema icónico contuviera en sí unos signos que fueran equiparables a los signos lingüísticos.

La base de la analogía de función que se pretendía respondía a la descripción de las tres características del signo lingüístico que había hecho Ferdinad de Saussure en su Cours de linguistique générale: linealidad, arbitrariedad y discreción, de las cuales las dos primeras no presentaban grandes problemas de aplicación, pero la tercera originó la gran polémica: si no podía encontrarse un esquema de funcionamiento discreto del signo pictórico no podía entonces hablarse con propiedad del sistema de comunicación visual como lenguaje.

El asunto pues pasaba por elaborar un examen profundo de la segunda articulación del lenguaje plástico, encontrar una nómina finita de iconemas que en combinación arbitraria fueran capaces de producir conceptos visuales de manera similar a cómo la combinación arbitraria de fonemas produce palabras en cada lengua.

De entre los defensores más entusiastas del lenguaje pictórico, el más destacable por su posición aproximadora entre los dos sistemas es quizás el profesor García Berrio, quien, a lo largo de varios años, ha venido defendiendo, en multitud de artículos y estudios monográficos, la posibilidad real de encontrar este grupo de iconemas teórico ${ }^{3}$.

se halla el viejo estudio de Lessing (cfr. Lessing, 1766, ed. cast. 1977), que se atrevió a evidenciar las diferencias de procedimiento y de significado entre la pintura y la poesía. En uno y otro sentido no han faltado estudios sobre las relaciones entre los sistemas de comunicación lingüísticos y los icónicos, especialmente en nuestro final de siglo, debido a la importancia general que le han conferido los progresos técnicos, a la imagen visual. El campo lógico de estudio se ha extendido hacia varias disciplinas académicas favoreciendo muy diferentes perspectivas. A Lessing, y a las comparaciones entre las artes que realizaron Hegel o Schopenhauer le siguieron, citando sólo los más importantes estudios de la época más reciente, críticos como Lee (1982), quien se acercó al problema desde la Historia del Arte a través de la Retórica, Praz (1970, ed. cast. 1979), también desde la Historia del Arte, Étienne Soriau (1947), desde la Estética comparada, o el grupo más importante de intelectuales que han dedicado sus esfuerzos a esta cuestión y de los que hablaremos más adelante: los semiólogos, entre los que cabe destacar por su especial dedicación a Eco, Barthes, Garroni, Lotman, Schefer, Uspensky, Nebesky o García Berrio entre otros muchos, quienes, con criterios muchas veces divergentes, han ido tejiendo en los últimos años las líneas de pensamiento fundamentales respecto a este problema.

3 Por un orden cronológico, los textos donde el profesor García Berrio defiende su postura son: G. Berrio (1981: 14 y ss.), donde ya apunta hacia la posibilidad de encon- 
Por otro lado, gran parte de la crítica semiológica señala claramente la condición metafórica del lenguaje pictórico. El más destacado a nuestro juicio es Schefer, quien argumenta que la pintura no es una lengua en tanto en cuanto sólo puede leerse gracias a los límites lingüísticos, geométricos, etc., esto es, dentro del espacio epistemológico del que se constituye en punto de reunión de aquello que significa. Schefer admite que un cuadro sea analizable en términos de sistema en cuanto que un cuadro no se manifiesta en el espacio en que ha sido constituido sino por la implicación de las teorías que supone.

La postura de Schefer está muy cerca de los postulados de la deconstrucción (analizar la imagen no consiste en aislar sus partes constitutivas, sino en descubrir en ella los textos que han sido implicados, incluso nuestras propias lecturas), pero también de la mitocrítica estructural de Durand, en cuanto que el valor de estabilización de contenidos en un cuadro se produce en la medida en que éste trasmite el símbolo como imagen ${ }^{4}$.

Es, sin embargo, evidente que es posible formalizar una lectura de la obra pictórica como sistema, sobre todo en los niveles superiores de análisis. La teoría de la composición pictórica que se imparte en las Escuelas de Arte no deja de presentar en el fondo una analogía funcional con la aplicación del estudio de la «dispositio» retórica, de la cual, a nuestro juicio, dependió siempre a través de la influencia en todas las artes que disfrutó la retórica clásica.

La propia crítica artística ha llevado muy lejos, y a buen término, sus estudios de los niveles superiores de la estructura lingüística del texto

trar estos elementos, el artículo-catálogo: G. Berrio, Hernández, (1984), donde abiertamente habla de una fonología característica del pintor Ortíz Sarachaga, G. Berrio, Hernández (1985-1986: 52-57, especialmente), y su último estudio, hasta la fecha, que resume y sistematiza su poética del arte visual: G. Berrio (1988: 44, especialmente), donde hace alguna reflexión práctica sobre qué elementos pictóricos podrían ser catalogados como elementos pre-significativos (este es el nombre que él da a lo que nosotros denominamos iconemas), haciendo referencia a la mancha de color como candidato firme a establecerse como elemento significante desarrollada a través de su producción mediante lo que serían los colores puros o las tintas industriales básicas que componen la mancha resultante.

4 García Berrio (1988: 38-41, notas 6, 7 y 9) ofrece una nómina extensa de referencias sobre las distintas posturas de las diversas escuelas críticas que han abordado el problema, por lo que nosotros aquí no lo volveremos a hacer. Es interesante (García Berrio, 1988: 41, nota 9) observar el valor que otorga García Berrio a la semiología orientada hacia la lectura (Marin y Schefer fundamentalmente). Para este autor esta crítica inmanentista es preludio de los «años de entusiasmo» semiológico por la pintura como lengua, presentando el problema entonces como apreciación antagónica entre la crítica semiológica nacida de la teoría de la recepción y la nacida de la lingüística del texto que él encarna como uno de sus mejores defensores a nuestro juicio. 
plástico. Los estudios de Francastel (1969) sobre la figura, correlato posible en términos amplios de una morfología pictórica 5 . Los estudios iconológicos de Panofski, donde converge el interés por la materia poética como forma general de la comunicación simbólica con la evidencia de una semántica textual muy elaborada, y donde se manifiesta también el complejo entramado de relaciones entre la sintaxis compositiva y el significado cultural del discurso plástico ${ }^{6}, 0$, incluso, lejos en el tiempo ya, el ensayo de Alois Riegl que intentaba mostrar la evolución histórica del sistema de representación plástica, incluso casi explícitamente, y haciéndose contemporáneo a la moda de los estudios lingüísticos de la época, como un sistema parejo al lingüístico (y por tanto con una gramática discernible $)^{7}$, manifiestan un dominio de la

5 Francastel (1969: 9 y ss.) desarrolla el estudio de la forma pictórica en relación a su contexto composicional (en definitiva sintáctico), pero ateniéndose a un concepto muy moderno para los años de redacción de sus estudios. Sin proponerselo, pero bien intuido, Francastel, intentando destruir, precisamente, el paralelo no metafórico entre la comunicación visual y la comunicación lingưística en el nivel poético, designa como garante de la generación de la forma pictórica a la representación global del cuadro, esto es, a lo que la moderna lingüística viene llamando texto o discurso según los casos. Francastel, sin embargo, desarrolla su teoría de la disimilitud entre los dos lenguajes sobre unas bases linguísticas poco profundas, lo que genera cierta confusión en sus argumentos de relación entre los dos sistemas. Uno de los errores más extendidos, y de los que Francastel participa, como otros muchos investigadores, incluso lingüistas, es el de equiparar dos niveles comunicativos diferentes, el nivel lingüístico puro (de comunicación) con el nivel de representación visual artístico. Al nivel artístico le corresponde el nivel poético, no el estrictamente comunicativo, aunque un texto poético sea también un acto simple de comunicación. Por otro lado Francastel cree que es la simple adición fonémica la que genera la palabra (él habla impropiamente de sílabas), es evidente ya, sin embargo, que la arbitrariedad del signo lingǘístico implica unas condiciones en el imaginario cultural que limitan y encauzan la combinación de fonemas ajustándolos a la cultura a la que sirven. (Sin ir más lejos podemos pensar en la vieja teoría romántica humboldtiana que desarrolló el idealismo lingüístico de Spitzer y demás sobre el volksgeist, pero no sólo en ella, baste mencionar la antropología linguística de más reciente cuño, Durand sólo como ejemplo, para, cuando menos, admintir a juicio esta observación).

${ }_{6}^{6}$ Los muy conocidos Estudios sobre iconología (Panofski, 1962), muestran el profundo conocimiento de Panofski sobre la semántica del símbolo y la estructura de su trasmisión, el Pandora's box, The changing aspects of a mithical symbol (E. y Dora Panofski, 1956) completa la visión general panofskiana del símbolo como funtor de la trasmisión del significado simbólico ejercitándose en un ejemplo completo de seguimiento de las transformaciones de una materia poética (a este respecto nosotros nos propusimos mostrar aspectos semejantes de la trasmisión del símbolo en las materias poéticas literarias en nuestra tesis doctoral La Leyenda del Caballero del Cisne. Historia de una materia poética, tesis en proceso de publicación en microficha por la Universidad Autónoma de Madrid, que fue defendida el 29 de Abril de 1993 en esta universidad). El estudio de la forma simbólica, concepto recogido por Panofski de la filosofía simbólica cassireriana, y de indudable productividad, se convierte en una verdadera morfosintaxis general que pliega sobre el significado de la obra pictórica su propia estructura de espacio organizado en Die Perspektive als «Symbolische Form» (Panofski, 1924-1925).

7 Cfr. RIEGL, (1897-1898, ed. ital. 1983). En la segunda versión del libro, la que realizó para sus lecciones del curso de 1899 en la Universidad de Viena pude leerse: 
concepción sistemática de la expresión plástica que muchos de los críticos de formación artística, entre los que quizás el más sobresaliente es Rudolf Arheim, afirmaron implícita o explícitamente sin rubor ${ }^{8}$.

Ahora bien, ¿es realmente preciso descender al nivel del significante y mostrar la viabilidad y operatividad analógica del signo plástico y el signo lingüístico, o simplemente debemos movernos en el terreno de una analogía general de funcionamiento epistemológico?

Quizás el problema sea más un problema de concepción del propio lenguaje natural (la concepción estructural que en el fondo lo suscita) que una cuestión real que afecte a la propia definición del arte como sistema, en cualquier caso, se han dado muy pocos pasos prácticos para afirmar o negar realmente la dimensión que pueda tener la segunda articulación del signo icónico, apuntándose sólo posibilidades teóricas fundamentadas, pero no estudios prácticos que descubran estas unidades.

Intentando avanzar sobre la hipótesis del profesor García Berrio de la existencia efectiva de estas unidades, y teniendo en cuenta que el caballo de batalla es el de su definición y descripción, debiendo llegar al final a una nómina de iconemas, o de rasgos distintivos que elaboren, nosotros intentamos llegar a ella, siendo enormes los problemas con los que nos encontramos.

En primer lugar, tuvimos que afirmar la presencia de materia significacional en el significante plástico. Desestimar la semántica del color o de la forma fuera del contexto de la figura era ciertamente una contradicción con la realidad pictórica, no sólo en la abstracción post-kandinskiana, sino incluso en la figuración (¿quién puede dudar del color naranja con que se define al hombre representado en Melancolía de Sérusier, por ejemplo?). Esta presencia de sentido en los elementos pre-significativos no plantea sin embargo mayores dificultades a la luz de los ya muy viejos estudios sobre el significante lingüístico en poesía

"Ogni opera d'art parla un suo determinato linguaggio artistico, anche se naturalmente gli elementi dell'arte sono diversi da quelli del linguaggio. Ma se esiste un linguaggio dell'arte deve esistere una sua grammatica storica, naturalmente anche solo in senso metaforico». (Riegl, 1983: 270).

8 Cfr. en especial el trabajo de Arheim Art and Visual Perception. A Psychology of the Creative Eye (Arheim, 1954, ed. cast. 1985). El compromiso de Arheim en este texto con una visión lingüística de la comunicación visual es muy claro (cfr. 1985: 59 y ss. para observar el desarrollo del paso de significante a significado en la forma plástica según Arheim). Sus leyes de la simplicidad: simetría o no, una sola dirección o varias, centro común y conformidad a la armazón espacial de orientación vertical y horizontal (cfr. 1985: 72 y ss.) fueron muy tenidas en cuentas en nuestro intento de elaborar un sistema de significantes para la comunicación plástica. 
del formalismo ruso ${ }^{9}$. Ahora bien, ¿cómo deslindar entonces las dos articulaciones del signo plástico?

Partiendo de las indicaciones y sugerencias de trabajo que me hizo el profesor García Berrio cuando fui alumno suyo, alguna de las cuales aparecen reflejadas en su $U t$ pictura poesis ${ }^{10}$, comencé por superponer las teorías saussureanas sobre la discreción del signo linguiístico a los posibles significantes plásticos para de ese modo establecer la nómina teórica de iconemas. Esta nómina debía ser capaz de generar, por combinación, todo el espectro morfológico de la pintura occidental que podía considerarse como unidad lingüística. La gran revolución del arte plástico del siglo $\mathrm{xx}$, la abstracción, tendría entre una de sus muchas causas internas, en el nivel pre-significacional, la reducción del sistema iconémico que, por ejemplo, se manifiesta en la sistemática utilización de colores puros de la obra de Paul Klee o en el aformalismo pictórico de Pollock.

Parecía evidente que el sistema iconémico pretendido estaba conformado por, al menos, dos materias significantes diferentes (como el sistema lingüístico lo está por dos sistemas de fonemas diferentes: el vocálico y el consonántico), de tal manera que el color era el candidato primero a ser investigado como tal, pero, junto a él, no podía negarse que a éste se le unía al menos un sistema de formalidad lineal que lo completaba dando sentido al dibujo y otras artes monocromáticas que podían trasmitir formas pictóricas con significado. La dualidad que presenta un dibujo a lápiz no es de alternancia de color, sino de luz en una gama única, y por tanto, presentar al color como único sistema suscitaba dudas razonables a la investigación.

La primera idea global fue presentar el triángulo de Goethe (formulado a partir del disco de Newton) ${ }^{11}$ como el esquema básico de rasgos

9 No abundaremos en la posición formal anticontenidista del formalismo ruso ni en sus investigaciones sobre la transracionalidad del significante poético que son de todos conocidas. El mejor texto-manual que conocemos donde estas cuestiones quedan aclaradas de sobra es quizás, al margen de los propios textos del formalismo (cfr. sin ir más lejos el texto de Sklovski, Viktor, La cuerda del arco (sobre la disimilitud de lo símil) (ed. cast. 1975) y donde además se discute el problema del texto plástico), el del propio profesor Antonio Garcia Berrio (G. Berrio, 1973), redactado ya hace bastantes años pero no por ello menos lúcido.

${ }_{10}$ Nos referimos, por ejemplo, a la observación mencionada antes sobre la mancha de color o sobre la utilización del esquema de trabajo de la fonología generativa (Cfr. por ejemplo Schane, 1979). Cfr. también García Berrio (1988: nota $n^{\circ} 6$ ).

${ }_{11}$ Para la teoría del color de Newton puede verse la edición de Londres de la Óptica (Optiks: or a Treatise of Reflections, Refractions, Inflections and Colour of Light), del año 1730. (Hay también además de las modernas, una edición latina publicada en Padua en 1749). La teoría de los colores de Goethe, Zur Farbenlehre (Goete, 
distintivos que formaban los colores del espectro físico, y, obtenidos éstos, constituirlos en iconemas del primer sistema de significantes plásticos. Así, los rasgos distintivos sobre los que operar en un principio eran: [ \pm Rojo], $[ \pm$ Azul] y [ \pm Amarillo], cuyas combinaciones proporcionaban el resto de los colores denominados fundamentales, esto es, los del arco iris.

Este sistema proporcionaba un corpus limitado de unidades pre-significativas aceptable, sin embargo, a la hora de fundamentar las analogías con el sistema de alófonos de la lengua natural debíamos defenderlo con rasgos de tipo semántico que no eran satisfactorios como tales para el sistema.

Fijamos entonces nuestra atención en la diferenciación que la física hace del color a través de su longitud de onda, sometida a una sencilla ecuación y que proporciona una estabilidad física a la materia significante muy similar a la del sonido como materia del significante lingüístico. La fórmula de la longitud de onda es:

$$
\lambda=c \mathrm{~T}=\frac{c}{f}
$$

donde la longitud de onda $(\lambda)$ se obtiene multiplicando la velocidad de propagación de las ondas electromagnéticas $(c)$ por el período $(T)$ o dividiendo la velocidad por la frecuencia $(f)$.

La longitud de onda del espectro visible va, desde la luz violeta $\left(4 \cdot 10^{-5}\right)$, hasta la luz roja $\left(7 \cdot 10^{-5}\right)$, cuyas frecuencias, obtenidas por deducción de la ecuación antes expuesta, son de $7,5 \cdot 10^{14}$ hertz para el violeta y $4,3 \cdot 10^{14}$ hertz para el rojo, entre esta banda de radiaciones se sitúan los colores del arco iris que se mueven en bandas de frecuencias intermedias. El problema de las variantes contextuales (alófonos para el lenguaje natural y sin determinar nombre para la lengua pictórica) quedaba pues sometido a una cuestión de posición del mismo dentro de la banda de frecuencia que definía el color en cuestión.

El problema de las tintas industriales no afectaba significativamente al sistema en cuanto que, reducido el problema a una cuestión física no

1810) refleja el espíritu newtoniano de empresa doble científico-metafísica. Un estudio histórico muy completo de las diversas teorías sobre el color que abonaron el campo de la investigación artística y que reúne además abundante bibliografía sobre el tema es el de Mario Brusatin (1983). 
se presentaban complicaciones más importantes de las que se le presentan a la moderna fonética. La abstracción del iconema era una abstracción, de hecho, de la síntesis de toda la banda de frecuencia en la que se movía aquello que designábamos como tal o cual color.

Sin embargo, el sistema de color no es el único que opera en la comunicación visual. La textura, el soporte material de la obra y otros elementos como los grafismos y las estructuras lineales juegan un papel importante en este sistema de comunicación. Todos estos elementos citados, con la excepción de las estructuras lineales (incluidos, evidentemente los grafismos como tales) podían ser asignados analógicamente al grupo de los elementos suprasegmentales del sistema lingüístico natural.

El sistema de formalidad, llamado así por designar de alguna manera el complejo de líneas que aparecen sobre el plano y que, en su combinación, hacen perceptible la representación de una figura, ha sido estudiado varias veces, aunque por otros motivos, como matriz direccional de la comunicación plástica. El caso más evidente es quizás el pequeño estudio didáctico que hizo Kandinski, su famoso Punk und linie $z u$ fläche ${ }^{12}$, que demuestra ser un primer paso en la sistematización del comportamiento de los elementos geométricos básicos utilizados en pintura.

El sistema de elementos sobre el plano que combinados pueden generar la percepción de una forma resultante con significación (lo que se denomina figura) requiere para su estudio, como premisa, una depuración de los elementos que lo integran. En primer lugar, considerar las formas geométricas que pueden aparecer sobre un plano nos lleva a la insolubilidad de la cuestión por la infinitud de posibilidades que ofrece. Es necesario pues convenir en que estas formas son productos significacionales elaborados a partir de elementos significantes más pequeños. La geometría euclidiana proporcionaba unos elementos básicos sobre los que operar, sin embargo, y a pesar de la sencillez expositiva y su generalmente admitida operatividad funcional, no se ajusta por completo a la nueva física que es capaz de definir el universo como curvo.

Sobre un plano, que es en definitiva el soporte físico-geométrico de un cuadro, hay puntos y líneas, materiales de los que se nutre la comunicación visual, combinados con las ausencias, los vacíos que muestran superficies perceptibles también como significados en una representación pictórica. Haciendo abstracción de la definición euclidiana del

12 Texto de 1926 (Dessau). Trad. cast. Kandinsky 1984. 
punto, puesto que, como se hacía evidente a Kandinski y a todos los demás, el punto pictórico es en realidad un conjunto de multitud de puntos (el punto geométrico como tal no tiene dimensión espacial), tenemos, sin embargo, que proporcionar un esquema más preciso de los iconemas de este sistema. Hay líneas rectas y curvas, infinidad de líneas en alternancia libre (que llamamos grafismos) que no muestran una definición precisa de sí mismas obligando a la mente humana a separarlas simplemente por oposición entre unas y otras y por dimensión relativa en el conjunto.

Definir un cuadro, o un triángulo, por el número de grados que suman sus ángulos, puede ayudar a sistematizar el proceso de construcción de una forma visual, pero no de manera completa. Una primera aproximación, muy defectuosa desde su base, nos llevó a considerar los siguientes rasgos distintivos para el sistema de gráficos sobre el plano: [ \pm dirección] y [ \pm angularidad]. Ahora bien, el rasgo de angularidad no podía considerarse como tal en cuanto que no proporcionaba de por sí más que una división entre superficies y líneas, y no conseguía diferenciar siquiera un triángulo de un cuadrado (los dos poseían el rasgo de [+ angularidad]. Era pues necesario continuar por otro camino aun cuando fueran válidos estos dos rasgos para separar dos tipos de elementos del sistema. Definir las superficies por el número de lados, forma clásica de definición geométrica, alargaba la lista de superficies posibles hasta el infinito, y, aunque en la práctica la lista fuera grande pero limitada, siempre había la posibilidad de topar con una superficie de más lados (esto es, de mayor número de grados en la suma de éstos).

Otro asunto era la irregularidad de las superficies. El rasgo de $[ \pm$ regularidad] aislaba una clase de polígonos de otros, estableciéndose así una nueva división en la ya practicada, pero aún insuficiente. Se acababan las posibilidades. Podía hablarse de la existencia de unas superficies geométricas básicas que eran definidas por la frecuencia de su utilización pictórica, y porque, en definitiva, una superficie mayor podía resolverse mediante la composición de ésta a través de varias de ellas unidas, como mostramos en la figura que aparece abajo al margen, donde una muestra de una triangularización, que podía prolongarse hasta el infinito teóricamente, desarrollaría los polígonos regulares que fueran necesarios.

La irregularidad sería entonces una cuestión dependiente de una alternancia libre de la angularidad del polígono. Ahora bien, la figura siguiente que construye polígonos no es, de hecho, sino un conjunto de 
líneas secantes de acuerdo con una posición relativa, esto es, un punto, sobre el cual gira toda la construcción, y que no es sino el eje sobre el que se desarrolla el círculo que inscribe el resto de polígonos:

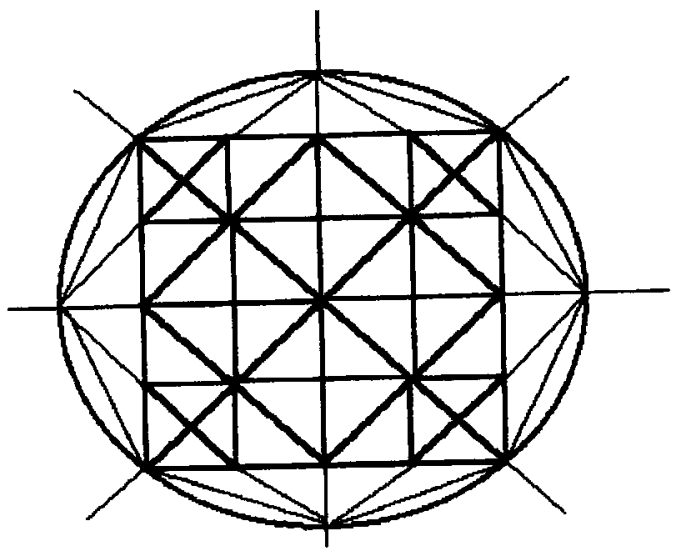

Siendo esto así, debiéramos poder afirmar que este segundo sistema de la comunicación pictórica no contiene más que un único rasgo distintivo que genera sin embargo multitud de iconemas, lo cual resultaría absurdo, o bien que, tomando como rasgos base el punto y la línea, sin hacer distinción entre curva o recta puesto que una línea recta puede definirse perfectamente como una sección de una circunferencia cuyo radio es infinito, resolver como pretendía Kandinski que existen dos iconemas básicos (punto y línea) que se proyectan sobre un plano y que, repetidos en combinación libre generan todo tipo de formas.

El asunto tenía su interés aunque probablemente seguía siendo tan confuso como al principio. La pregunta era, ¿podía considerarse entonces el mismo iconema dos líneas rectas de longitud diferente $o$ dos secciones de curvas cuyos hipotéticos radios fueran de longitud diferente? Y todas estas preguntas, y muchas más no impedían ni por un momento realizar una lectura de un cuadro, o de todo el conjunto de la obra de un pintor, una escuela, o una época acudiendo al tipo de estructuras básicas (color y formas) que empleaban, y afirmar entonces que a través de ciertos elementos constitutivos básicos Klee, o Leonardo, ordenaban el espacio de su discurso plástico.

Nuestra posición hoy se aleja un tanto de la del profesor García Berrio, con el respeto profundo que merece el maestro. Él mismo no dejaba de insistir, en su ensayo sobre Enrique Brinkmann, que era posible afirmar la condición no metafórica de la pintura como lengua- 
je, posición que en el Ut pictura poesis, aun manteniéndose en la certeza de la convergencia entre los dos discursos, encuentra sin embargo problemas como, por ejemplo, el de la arreferencialidad de la pintura mironiana, escollo que García Berrio salva a través del concepto de la autorreferencialidad poética.

Nosotros estamos convencidos de la posibilidad de acometer el examen de los discursos plásticos a través de la óptica lingüística en tanto que, como el lenguaje natural, la comunicación pictórica resume el mundo emblematizándolo y convirtiéndolo en símbolo de nuestra propia relación con la naturaleza, y esa operación nos permite la transformación del cosmos de la misma manera que lo hace el lenguaje. En la mente de todos aparecerá el recuerdo de la vieja cuestión: ¿Es el arte el que imita a la naturaleza o la naturaleza la que imita al arte? Sin embargo, al tomar esta posición y obligarnos a llegar hasta el final, cabe la posibilidad de que no sea posible la analogía en el funcionamiento de los elementos internos del sistema, aun cuando el resultado sea el mismo, la posibilidad de construir el símbolo de nosotros mismos y el mundo.

La derivación hacia los componentes del imaginario humano es casi obligada, como de hecho también García Berrio deriva su análisis hacia estos esquemas de apreciación fantástica ${ }^{13}$. Pero, los componentes imaginarios, residen dentro de un sistema pre-lingüístico, y no lingüístico según Durand (1979: 19, donde Durand recoge las ideas expuestas en Les structures anthropologiques de l'imaginaire). Este autor establece tres dimensiones que definen tres categorías de símbolos. La primera dimensión es la que él denomina mecánica, que define al aparato simbólico por analogía a lo que Freud llamaba aparato psíquico, y que, por tanto, puede sufrir lo que se denomina descalificación simbólica, esto es, una pérdida de intensión sémica que lo sitúa en el nivel del signo, llevándonos entonces a suponer una relación de filiación entre signo y símbolo que a nosotros nos resulta difícil de ser sostenida. Esta dimensión es denominada por Durand nivel verbal.

Este nivel verbal es el primer lenguaje (que es prelingüístico claramente en Durand): la expresión corporal, que, en tanto que verbo es acción de lo prerreflexivo (según terminología de Husserl), y no se reduce a la obsesión por el agujero (Freud), ni al juego de palabras de

13 Véase, sin ir más lejos, su artículo sobre Saura (1984), o la importancia que adquieren estos componentes como elementos de la hermenéutica plástica en (1988), que hace explícita en los capítulos V y VI. 
un lenguaje natural (Lacan), sino que se conforma como el esquema previo a todo: el enderezamiento postural ${ }^{14}$.

La segunda dimensión la constituyen las imágenes arquetipales, que a su vez se dividen en epítetas y sustantivas según si se trata de «cualidades sensibles» o «perceptivas», haciéndose más específicas bajo la influencia calificativa de las incidencias puramente exógenas: clima, tecnología, estado cultural...

Es en esta segunda dimensión donde se encuentra el símbolo stricto sensu. El ejemplo propuesto por Durand es la imagen arquetipal del Oriente, en el que convergen el conjunto simbólico del sol amaneciendo en las montañas o en las tierras desérticas, vinculado al color dorado de la arena.

La imagen arquetipal que propone Durand no es, sin embargo, a nuestro juicio, sino lo que la poética del texto denomina «tópico» aplicado a una imagen social (cultural) en vez de a un discurso, teniendo en cuenta que esta imagen social no es otra cosa que un discurso. Durand, expone además que el fonetismo de los lenguajes naturales añaden unas derivaciones específicas al aparato simbólico, estableciendo nuevas evocaciones distorsionadoras del significado primitivo, sin embargo (tercera dimensión), y, aunque coincidimos con él en esta afirmación, Durand supone una prioridad de los lenguajes naturales frente a los denominados «artificiales» que nosotros no estamos en disposición, por la evidente falta de datos probatorios, de aceptar plenamente.

Esta suposición a priori favorece que, más tarde, cuando hace el análisis de los textos visuales de Durero y el Bosco y de Rubens y Rembrandt, su discurso no haga sino enfrentar los tópicos culturales (en el sentido antes descrito por nosotros) que delimitan los estilos pictóricos. El caso de Rembrandt y Rubens es en este sentido llamativo, al terminar sosteniendo, en definitiva, aquello que la crítica de arte ya había constatado a principios de siglo (Wölflin en 1915) sobre la raíz católica de la exuberancia del pincel de Rubens y la protestante de la luz rembrandtiana.

Por otro lado, las derivaciones producidas por los lenguajes naturales comprometen, según Durand, al símbolo con particularismos culturales que convierten a éste en un sistema, esto es, le hacen perder su

14 Es aquí pues donde Durand sitúa los esquemas de apreciación imaginaria a los que reduce el enfrentamiento del hombre con la naturaleza en Las estructuras...: verticalidad, horizontalidad (ascensión y caída), cerco, ámbito... 
plurivocidad, subsistiendo de él únicamente el signo arquetipo. Es lo que se denomiuna "particularización histórica».

Esta afirmación, que nos parece correcta de base, aun cuando la causa que produce esta designificación primaria y la subsiguiente asignación histórica de significado no creamos que sea algo tan simple, produce sin embargo la impresión de una obligada evolución degenerativa del símbolo, conclusión a la que por otra parte ya habían llegado Müller o Robert en los años finales del siglo pasado y principios de éste y que nos conduce a la discusión sin fin sobre el carácter del progreso del entendimiento humano de la naturaleza ${ }^{15}$.

La superación de las tesis de Robert o Müller pasa en Durand por negar a la definición del símbolo la característica de arbitrariedad, lo que desde luego allana enormemente el camino de la crítica semiológica de las artes plásticas de origen lingüístico que se enreda, como estamos viendo aquí, en la búsqueda de la segunda articulación del lenguaje pictórico sin obtener frutos claramente satisfactorios, y hace, en gran medida, innecesarias nuestras líneas. Si el parámetro de análisis de las actuaciones «civilizadoras» del hombre en el mundo es su condición de símbolos (de instrumentos de la mediatez de la comprensión humana de la naturaleza) no debe entonces preocuparnos en absoluto el patrón estructural de conformación de los lenguajes, pues en éstos no se halla la significación plena de estas actuaciones, sino la evocación que resulta de la compresión del símbolo que encierran.

La pregunta entonces es: ¿y cómo es posible liberarse de la tiranía de la arbitrariedad?, ¿no nos hallamos condenados a sufrir eternamente la entropía del significado a consecuencia de nuestro instrumento único de contacto con el mundo que es nuestro lenguaje natural?

Nosotros pensamos que esto es precisamente lo que Durand se propone en su modelo de análisis, adentrarse en los túneles subterráneos del significado en su estado puro «prelingüístico», y esto es hablar en definitiva de noumenos, esto es: kantianismo estético, y Durand no lo niega, y lo muestra con orgullo cuando afirma que la semántica es, cuando menos, una poética (Durand 1993: 72).

15 Cfr. de forma general Müller (1856) y Robert (1915). Entre los españoles, Guichot y Sierra (1903) es también un ejemplo de esta concepción degenerativa del símbolo. De cualquier forma, ya en el siglo XVIII, C.F. Volney había puesto las bases de esta consideración al establecer la evolución de las sociedades y las religiones. El iluminismo ateo de Volney a veces le hace caer en este degeneracionismo estructural (entropía de significados) que compartirán de alguna manera, aunque desde presupuestos muy diferentes, en los albores de nuestro siglo Robert o Müller (Volney, 1822). 
La reflexión sobre el símbolo nos conduce, como conduce a Durand, a la definición del mito como un sistema simbólico, y como tal sistema de apropiación de la naturaleza, éste puede ser entendido como lenguaje, en tanto en cuanto que la comunicación es una de las consecuencias, no la única, de la función simbólica (en términos de Cassirer que Durand utiliza), y todo lenguaje humano es, ante todo, donador de significación, siendo por tanto el mito lenguaje como ya apuntó Lévi-Strauss (1953: 272; Merquior, 1977: 18 y ss.), un lenguaje que trabaja por encima de la arbitrariedad del signo linguístico sobre el que se desarrolla pero al que supera, pero también, en nuestra reflexión sobre el texto plástico, nos lleva a la misma conclusión obligada haciendo recaer todo el peso comunicativo de las artes plásticas en su relación con el símbolo, y, ¿por qué no?, también a arrastrar hacia él al propio sistema de comunicación natural ${ }^{16}$.

Quizá entonces debiéramos plantear otra cuestión de las que nunca tendrán una respuesta rotunda, incluso puede que ni siquiera una respuesta, la de la independencia del pensamiento y el lenguaje, pero aplicada a todos los sistemas que podamos denominar lenguajes, metafóricamente o no. Categorías como discurso o texto se nos antojan entonces más universales, metacategorías del sistema de relación del hombre con el cosmos, y no categorías lingüísticas.

Si esto es así, es indudable que podemos hablar de discursos plásticos, de cuadros como textos, y ¿por qué no?, entonces aplicar las reglas constitutivas de estas estructuras supralingüísticas (textos, discurso) y organizarlas en unidades de análisis, las cuales habrá obligatoriamente que estructurar, no a través de un esquema de filiación que tenga en su origen el sistema de la lengua natural, sino en un esquema de igualdad general que se pliegue a la exigencia propia de su utilidad comunicativa y, sobre todo, transformacional.

Los elementos significantes de cualquier sistema dependen de su constitución material, como ya Saussure entendió y nadie niega. Esta

16 En definitiva la construcción de modelos (razón última del símbolo) es el objeto del arte, de la religión... Ateviéndonos a enunciar una hipótesis general quizás poco gratificante para la soberbia de nuestra civilización (que en el fondo ya formularan Jung, Cassirer y otros muchos), el arte puede no ser otra cosa que el sustituto de la magia (ya desde las Lecciones de Estética de Hegel se apuntó la idea de que la estética venía a ocupar el papel de la metafísica en la cultura romántica y luego subsistió la idea aplicándola a la etapa postromántica que aún hoy vivimos). El homo faber, el transformador, genera modelos en la impotencia de volver a la Edad de Oro de su unión simpatética con la naturaleza. El arte posee la misma capacidad operacional que la palabra mágica del chamán, pero con carácter de realidad virtual, conformándose como la imitación de la palabra primordial de toda creación en cualquier mitología: ;Fiat lux! 
condición material tundamenta, en alguna medida para nosotros hasta hoy oscura aún, la propia sustancia del signo que organiza el sistema, de tal manera que, a nuestro juicio, la analogía, sobre todo la analogía direccional, esto es, la que pretende adaptar un signo de un sistema en virtud de otro ya definido, entraña riesgos y problemas como los que nosotros hemos pretendido mostrar en estas líneas. La postura de Schefer, por ejemplo, es limpia porque no se compromete, todos podemos estar de acuerdo en el compromiso de la experiencia (Derrida) y de la cultura (Jung) en la resolución del significado de cualquier discurso, ahora bien, es necesario continuar más allá y valorar la convergencia de significados, de evocaciones para utilizar la palabra romántica, como una confluencia cooperativa de la capacidad humana de la comunicación ${ }^{17}$.

Las investigaciones prácticas que nosotros realizamos sobre la teórica posibilidad de que existiera una segunda articulación en el signo plástico no fueron del todo improductivas, aunque dejemos al hipotético lector de este artículo sin la agradable sensación que produce el haber solucionado un problema. A pesar de que sería ciertamente posible seguir en esta dirección como posibilidad teórica, y consideramos que no se ha agotado, ni mucho menos, este campo de actuación sobre el hecho pictórico que nosotros aquí hemos esbozado, y que esperamos sinceramente que alguien retome, hoy, y a la vista de las dudas que nos asaltan una y otra vez, y de los problemas que se han intentado evidenciar aquí, creemos que es necesario intentar la superación del problema provocando una revisión en profundidad de muchas de las ideas que sobre la naturaleza general de los sistemas de comunicación la semiología ha ido generando. La posibilidad que nos abre el estudio en profundidad del símbolo como matriz pre-lingüística del pensamiento (aún a nuestro juicio todavía en su primera fase) ofrece nuevas vías para la investigación que pueden en un futuro facilitar la comprensión de las relaciones entre el significante y el significado (si como oposición es realmente pertinente) en el discurso plástico.

17 Como comentaba Francastel (1969: 91), la segunda articulación de los sistemas figurativos puede existir perfectamente, pero no como reduplicación de la primera articulación, no por combinación de elementos de la segunda articulación. El ejemplo que propone Francastel es evidente: quien dibujara una nariz y unas orejas, y las yuxtapusiera, no tendría por ello dibujado un rostro. 


\section{Referencias bibliográficas}

Arheim, R. (1954). Art and Visual Perception. A Psychology of the Creative Eye. Berkeley: The University of California Press [ed. esp. (1985). Madrid: Alianza].

Brusatin, M. (1983). Storia dei colori. Turín: G. Einaudi [ed. esp. (1987). Barcelona: Paidós].

CAssirer, E. (1972). Filosofía de las formas simbólicas. Trad. de Armando Morones. México: F.C.E., 3 vols., $\left[10^{a}\right.$ ed. al. (1964). Darmstadt: Wissenschaftliche Buchgesellschaft].

- (1989). Esencia y efecto del Concepto de símbolo. Trad. cast. de Carlos Gerhard. México: F.C.E. [1. ${ }^{a}$ ed. en alemán Darmstadt: Wissenschaftliche Buchgesellschaft (1956)].

DuRAND, G. (1993). De la mitocíritica al mitoanálisis. Figuras míticas y aspectos de la obra. Edición y traducción de Alain Verjat. Barcelona: Anthropos / México: Universidad Autónoma Metropolitana Iztapalapa [1. ${ }^{\mathrm{a}}$ ed. fr. (1979)].

Elíade, M. (1992). El Chamanismo y las técnicas arcaicas del Extasis. México: F.C.E., Reimpr. [Ed. fr. (1968). París: Payot, 1. ${ }^{a}$ ed. fr. (1958)].

FranCASTEL, P. (1969). La figura y el lugar. Caracas: Monte Ávila. [1. a ed. fr. (1967). La Figure et le Lieu. París: Gallimard].

Frazer, J.G. (1986). La Rama Dorada, magia y religión. México: F.C.E. [1. ${ }^{a}$ ed. ing., 2 vols. (1890), la ed. esp. procede de la ed. abreviada en inglés (1922). Nueva York; The Macmillan Company].

García Berrio, A. (1973). Significado actual del formalismo ruso. Barcelona: Planeta.

- (1981). Enrique Brinkmann. Semiótica textual del discurso plástico. Montpellier: C.E.R.S.

- (1984). «Antonio Saura: imaginario espacial y tiempo del hombre». Revista de Occidente 32, 127-146.

- (1988). Ut poesis pictura. Madrid: Tecnos.

-; Hernández, M. ${ }^{\mathrm{a}}$ T. (1984). Ortiz Sarachaga, esquema plástico y construcción imaginaria. Villarrobledo: Catálogo de la exposición organizada por la Caja de Ahorros en el Museo de Albacete.

-; HeRnÁndez, M. ${ }^{\mathrm{a}}$ T. (1985-1986). «Semiótica del discurso y texto plástico: del esquema textual y la construcción imaginaria». Estudios de Lingüística $3,47-85$.

Guichot y Sierra, A. (1903). Ciencia de la Mitología. El gran mito ctónicosolar. Madrid: Librería General Victoriano Suárez [reed. facs. (1989). Barcelona: Alta Fulla].

Goethe, J. W. (1810). Zur Farbenlehre. [(1910) ed. al. Tubinga. ed. esp. Buenos Aires: Poseidón (1945)].

KANDINSKY, V. (1926). Punk und linie zu fläche, Desau [ed. esp. (1984), con trad. R. Echavarren, Barcelona: Labor, procedente de la de Barral (1970) que recoge la francesa de Neuilly (Seine) de 1955].

LEE, R. W. (1982). «Ut pictura poesis». La teoría humanística de la pintura. Madrid: Cátedra [ed. ing: «Ut Pictura poesis». The Humanistic Theory of 
Painting, W. W. Norton \& Company Inc., procedente de estudios publicados cuarenta años atrás en el Art Bulletin].

Lessing, G. E. (1766). Lao Koon. Berlín: Christian Friedrich Voss [ed. esp. de E. Barjau. Madrid: Ed. Nacional (1977)].

LÉvi-Strauss, Cl. (1953). Anthropologie structurale. París: Plon.

LotMAN, Y. (1970). Struktura judozhestvennog teksta. Moscú: Iskusstvo [Trad. esp. de Victoriano Imbert: (1982). Estructura del texto artístico. Madrid: Istmo].

Merquior, J. G. (1977). L'esthétique de Lévi-Strauss. París: P.U.F.

Müller, M. (1984). Mitología comparada. Ed. y trad. P. Jarbí. Barcelona: Teorema [1. ${ }^{\mathrm{a}}$ ed. al. (1856)].

Newton, I. (1730). Optiks: or a Treatise of Reflections, Refractions, Inflections and Colours of Light. Londres. [trad. esp. (1977). Madrid: Alfaguara].

PANOFSKI, E. (1927). Die Perspektive als «Symbolische Form». Leipzig-Berlín: B.G. Teubner [orig. en Vorträge der Bibliothek Wasburg, hgr. von Fritz Saxl. Vorträge (1924-1925). Ed. esp. (1973), Barcelona: Tusquets].

- (1972). Estudios sobre iconologia. Madrid: Alianza [ed. amp. (1962) Studes in Iconology. Nueva York: Harper Torchbook \& Row Inc.].

-; PANOFSKI, D. (1956). Pandora's box, The changing aspects of a mithical symbol. Nueva York: Bollingen F. Inc. [ed esp. Barcelona: Barral (1974)].

Praz, M. (1970). Mnemosyne. The Parallel betwen Literature and the Visual Arts. Princenton: Princenton University Press [ed. esp. (1979). Madrid: Taurus].

RIEGL, A. (1897-1898). Historische Grammatik der bildenden Künste [ed. it. Grammatica storica delle arti figurative (1983), por F. Diano. Bologna: Capelli].

RoBert, C. (1915). Oidipus. Geschichte eines Poetischen Stoffs im Griechischen Altertum. Berlin: Weidmann, 2 vols. (El primero corresponde al texto y el segundo, a las notas).

Schane, S. A. (1979). Generative Phonology. Nueva Jersey: Prentice-Hall, Inc., Englewood Cliffs [ed. esp. Barcelona: Labor].

SCHEFER, Louis (1970). Escenografia de un cuadro. Barcelona: Seix-Barral.

ŠKLOWSKI, V. (1975). La cuerda del arco (sobre la disimilitud de lo símil). Barcelona: Planeta.

SORIAU, Ét. (1947). La correspondance des arts. Elements d'esthétique comparée. París: Flammarion.

Volney, C.F. (1822). Les Ruines, ou méditation sur les Révolutions des Empires. París: Bossange Frères Libraires [1. ${ }^{a}$ ed. 1791]. 